\title{
From Sigmund Freud to Michel Foucault: a study on sexuality
}

\author{
Gianfranco Tomei \\ Department of Neurology and Psychiatry, \\ "Sapienza" University of Rome, Rome, Italy
}

\author{
Corresponding Author: \\ Gianfranco Tomei \\ Department of Neurology and Psychiatry, \\ "Sapienza" University of Rome \\ Piazzale Aldo Moro 5 \\ 00185 Rome, Italy \\ E-mail: Gianfranco.tomei@uniroma1.it
}

\begin{abstract}
The studies on sexuality have been numerous over time, from the first analysis of the nineteenth century psychiatry to the accurate remarks of Michel Foucault. Psychoanalysis has taken much interest on sexuality, above all has tried to detect all forms of repression of libido society wielded on the individual since his early life. Following a period of repression of sexuality and of highly restrictive rules of conduct, according to many analysts including Herbert Marcuse, the Society has changed position on this topic adopting a whole new attitude, after 1968, more permissive and tolerant about the sexual practices of individuals. The scholar Michel Foucault has identified in the dichotomy between 'alliance device' and 'sexuality device" the evolution of the relationship of the social fabric with the sexuality. A relationship that form being highly prescriptive and limiting was becoming encouraging of the practices and of the general decriminalization, favoring a pervasive, imperceptible and invasive sexualization, for a hedonistic transformation of the existence based on consumption.
\end{abstract}

KEY WORDS: bio-power, eros, hedonism, libido, repression, sexuality.

Sexuality and all that concerns it has always been a thorny issue that has attracted many scholars who have attempted to decode its language and interpret its nature. From Sigmund Freud to Michel Foucault many philosophers, sociologists and psychologists, have dedicated themselves to interpret and describe different points of view and approaches around a central problem of the human existence. A clear detection of the energy that sexuality releases and constitutes its basis is a daunting task. Also because, as noted by Foucault, the dynamics of sexuality, in addition to its specific signs and languages, are dynamics that intersect with the power mechanisms of any given era. Sexuality and its language depend above all on the control that the Society applies on the individual, so that analyzing the mechanisms of sexuality means approaching the ways in which, in the different historical periods societies and cultures have thrown light on the problem or, on the contrary, have tried to suppress it.

Many scholars have tried to bring order to this incandescent matter. Sigmund Freud in "Three Essays on Sexuality" with the weapons of the rising psychoanalysis tried to give valid explanations and classify the various theories on sexuality. As it is well known, Freud led back all the phenomena of psychic life to the influence of libido, i.e. sexual energy (1).

For Freud the libido is the main thrust that drives the existence of man, and the neurosis that may be present in the individual comes from a poor psycho-dynamic management of these libidinal forces. The repressed or misdirected libido is harmful and leads most of the time to energy blockage that are little functional (2). In healthy subjects libido maintains a correct direction, in people who for a variety of reasons are sick the sexuality moves towards distorted path, diverges and flows in a pathological way. In the analysis conducted by the nineteenth-century psychiatry that took great interest in the sexuality but very often with methods not scientifically accurate; it was believed that when the sexual energy was not aimed to the primary goal of procreation, it gave rise to paraphilias and sexual deviancy $(3,4)$. Freud, however, without abandoning a positivist perspective on the problem, analyzes the peripheral forms of sexuality to try and shed light on them, on the deep motivations and the consequences they lead to for the individual who develops and cultivates them.

The libidinal energy is identified as 'uncanny' (5). The uncanny Energy is the one that wants to break the established habits and taboos taken for granted by the current culture. Freud thinks the Libido is animated by the internal drive of the id, by the instinctual and unconscious side of the individual's psyche. 'The uncanny', animated by the id, disturbs the normal psychic equilibrium, gives jolts up to the climax, to the earthquake of values, then it comes to redress a renewed balance. The 'uncanny' must be brought back to a proper management of the libidinal energy, otherwise it destroys the consolidated balance. In his studies on 
hysteria Freud identified the social repression introjected by the individual as the cause of psychic blocks and of a bad libidinal energy management. The problem of hysteria (from Hysteron: uterus; at that time a disorder associated directly to the female gender) soon became the focus of his work. The sexual block well of women in Vienna very often complained of, occurred during their childhood. The woman-child developed a sex rejection, or on the contrary was completely dominated by sex. The mental blocks that occurred in case of repressive mechanism could lead to a physical evolution: physical and motor blocks with the stiffening of one or more limbs, in some cases total paralysis. Freud describes numerous cases in his clinical studies.

It is to consider of course the social context in which Freud exercised his activity: the late nineteenth century Central European Vienna. A patriarchal society dominated by a conservative and traditionalistic bourgeoisie where everything that moved away from a very well defined order aroused a rigid and implacable social stigma. A time and a world that placed blocks to sexuality in the form of coercion and repression. The contradiction of the Freudian psychoanalysis is that it failed, it did not succeed in resolving the dilemma between the effort to normalize and the tendency to blow up dialectically the mechanisms of cultural and social repression that each society shows as a heritage (6). Wilhelm Reich continued Freud's studies coming to a radicalization of the psychoanalytic experience. With the works of Reich, in particular the "Sexual Revolution", the conformist view of the psychoanalysis is overcome. Following an actually Freudian scheme, Reich comes to a libidinal energy exaltation free from the impulse of death and the dry censorship of the superego: the libido must be free and freely move so to erotize every aspect of the individual's life, in order to break down the so-called "emotional barrier", which is a source of inhibitions (7). Through an effective development of the libidinal energy towards the outside, according to Reich, the subject may get rid of the negative energy present in his body and even prevent the onset of "energy blocks" that, if not properly approached and settled, could stagnate and be the root of what Reich called "biopathies" (8).

Other Authors who studied the phenomenon were the philosophers Gilles Deleuze and Felix Guattari. In their most important works, "Anti-Oedipus" and "A Thousand Plateaus: Capitalism and Schizophrenia", they trace the sexual dynamics of the modern man with the metaphor of the desiring machine. In AntiOedipus, the two Authors theorize an overcoming of the shallows where the post-Freudian psychoanalysis had ran aground: the Oedipus complex, which is the center of the Freudian psychic mythology, and theorizes the child's attachment to the mother figure and the feeling of hatred towards the father. For the psychoanalytic orthodoxy this was the center of the sexual and libidinal life of the child, the axis on which all its future emotional and sexual life will move. Deleuze and Guattari instead overturn the problem, cancel this imprisoning constellation and ride the wave of the new libertarian movements recovering some of the assumptions of Nietzsche: that man is an arrow shot toward the future and with his voracious libido breaks every chain and projects forward, pushed from eros and desire (9). Hence no Oedipal bonds, but a continuous attack to the reality under the indomitable impulse of the libido. Green light then to any desiring impulse, to a sexuality free from a procreative need, and at the same time to dissonant, unequal and heterodox sexualities. Deleuze and Guattari's vision was much criticized and considered dominated by the fashion of the time, but it enabled the overcoming of the obsolete psychoanalytic thought and the renewal of the vital impulse, the Elan Vital that many psychoanalysts risked to sacrify against the wall of the orthodoxy to the original theories (10).

The philosopher and sociologist Herbert Marcuse analyzed the sexuality in relation to the changes occurred after the end of World War II. Western societies were rapidly moving from a rural economy to a new industrial and post-industrial structure. In peasant societies the sexuality was a drive to be monitored. Marcuse turned his analysis to the work and the world of the factory. In his first analysis the bourgeois capitalist society is the cause of sexual repression: it forces the workers to exhausting working hours, and prevents them from wasting their energy in unproductive activities. The factory is the place where the individual's impulses are channeled off by the assembly line and the worker, drained of all his energy, leaves unable to develop his own libido satisfactorily. Eros becomes a tool that frees man from the bonds of the work and gives him the chance to live his life in a rich and satisfying way (11). With the text "Eros and Civilization" Marcuse gets in wake with the 1968 sexual liberation movements that considered work as a source of repression, while the sexuality allowed to release the energy suppressed from the industrial society. In the following decades his perspective is to be replaced by a different vision. From "Eros and Civilization" to "One-dimensional Man" Marcuse turned his interest to the de -sublimating power of sex. The paradigm is completely different: the time of repression of the sexuality gives way to a time of liberalization. Sex is promoted, encouraged, with the aim of giving to the masses an instinctual outburst and make the citizens consumers of luxuries. This leads to a form of repressive tolerance, that is the individual undergoes the liberalization not as a conquest but as a permission imposed from above, and sex becomes an instrument of control. The sexuality becomes a tool of manipulation of the masses that are projected in a world of consumerism where sex is the first instrument of subdual, playing on the instincts and the desire to consume (12).

In Michel Foucault we find a treatment of the topic which is in fact the sum of the essays on the sexuality that passed through the twentieth century. His analysis is linked in part to Freud and the psychoanalysts who succeeded him and approaches in a rather original way the relationship between the sexuality and the forms of power that have fallowed each other over the time. 
In many of his writings Foucault describes the Biopower. It is the control that the Power exerts on individuals at molecular level; not the supremacy of one social class over another, but all that network of rules, implementing pressure, adopted stances that each individual has marked on himself and in turn imparts to others. A network of rules and precepts that the society impresses imperceptibly on individuals and individuals on each other. In the field of the sexuality we have seen over time a paradigm shift: from the repression of the behavior and the prosecution of the discrepancy, to a dimension of disclosure and underscoring of the erotic practices, even the most hidden and eccentric. As Marcuse described, modern society has apparently weakened controls over the sexuality, which shows itself openly.

Foucault divided the models of sexuality related to the social practices into four well-defined categories:

- The Hysterical Woman: the psychiatry of the nineteenth century gradually explored the woman's body as "fully saturated with sexuality". The social body, the family space, the life of the children, gave the woman the double face of Mother and of her mirror image of "nervous woman".

- The Masturbating Child: according to this statement children give or are likely to give themselves to a sexual activity. The pedagogizzation of the sex of the child" is mostly evident in the war against onanism that in western societies lasted nearly two centuries.

- The Malthusian Couple: through the socialization of procreative conduct the couple has been empowered toward the State by means of incitement or brake, depending on the period, with "social" measures or tax, up to a medical socialization through birth control.

- The Perverse Adult: the sexual instinct has been isolated and analyzed as a biological and psychological self instinct, with a clinical analysis of all the pathogenic and abnormal forms of sexuality. The psychiatrization of perverse pleasure has taken place (13).

Foucault identifies other forms of power:

- Alliance Device: the system of marriage, of establishment and development of kin, the transmission of names and properties. This alliance device with the enforcement mechanisms that guarantee it lost its importance as the economic processes and the political structures could no longer consider it a suitable tool. The alliance device was structured around a system of rules that defined what was allowed and what was prohibited. It was also the religious control mode that prevailed until the early nineteenth century.

- Sexuality Device: this device operates on changeable, polymorphic and economic techniques of power. What is relevant are the feelings of the body, the quality of pleasures, the nature of the impressions although imperceptible.

While the alliance device is aimed at a homeostasis of the social body, is linked to the right, and has the re- production as a high point, the sexuality device has not its reason for existence in the reproduction, but in the innovation, it has to annex, to penetrate the bodies in an increasingly detailed way and to control it in its practices in a holistic and comprehensive manner (14).

Foucault calls this the Microphisics of Power and that kind of power means that the monitoring mechanisms are scattered in the ganglia of the society and the control of bodies and minds occurs through a decriminalization of "different" and minor (peripheral) sexual practices. The control and the hedonistic sexualization of individuals become for this reason scattered and pervasive, subtle and invasive (15).

According to many scholars from a highly censorious and prescriptive perspective on the sexuality it has gone to an encouragement of the sexuality. These scholars believe the modern society could no longer limit the Libido as in the past; so the phenomenon has rapidly evolved, also because of economic transformations. Minor sexualities have had the opportunity to legitimate and become part of the current talking of individuals. This liberalization of sexual practices has coincided with a change in the direction of a consumerist society, where the hedonism of practices and social attitudes was in parallel with the explosion of the market economy and with euphoriant social and interpersonal relationships (16).

\section{Perspective for the future}

The scientific literature, since the beginning of the last century until recent years, has focused on deciphering the language and the specific signs concerning the issue of the sexuality. Sexology with its references is the science that studies in detail this topic, while other types of studies were aimed at identifying the links between aspects of the sexuality and the socio-cultural surrounding context. We have seen how over time we have passed from an attitude of containment and repression, set by a patriarchal society that was hardly getting rid of a rural and peasant mentality, to a supposed attitude of "tolerance" that comes to encourage sexual practices and to consider them an instrument and an end of the hedonistic lifestyle of a modern "consumer."

It would be interesting to note, and it would be a useful perspective to be applied for the future, how the multiculturalism reacts to this situation. That is to say what might be the effects of the contact between immigrants of other religions and cultures with the sexual liberalism the citizens of Western societies have got used to in recent decades.

We know how other religions, in particular Islam, have a very different perspective on the subject: Arab societies suffer from a paradigm that has hardly evolved over time. In Islamic societies the sexuality is strictly banned from the topics that can be dealt with. Islamic culture has always relegated women to a completely subordinate role, and it still remains a taboo the idea, 
derived from psychoanalysis, that this topic can be approached playfully, outside of an optics strictly directed to the procreative function. Immigrants from these countries have shown particular resistance to get accustomed to the habits of the society where they are housed, above all with regard to this aspect of Western culture.

It would therefore be interesting to see what the effect of this mixture of culture will be, not so much with the first-generation of immigrants, who seem reluctant to any change in their practices on the topic, but with their children and successors, immigrants that is, of second, third or fourth generation. Will they remain faithful to the tradition passed on by their fathers, or will they absorb the habits of the host countries, opting for a sort of liberalization in the field of sexual practices?

Multiculturalism in the field of sexuality is a topic yet to be analyzed, and an accurate analysis will be able to understand and identify even better the trend lines that the phenomenon plays in this historical period.

\section{References}

1. Freud S. Tre saggi sulla sessualità. Newton-Compton, Roma, 1992.

2. Freud S. Isteria e angoscia. Bollati Boringhieri, Torino, 2001

3. Kraftt-Ebing R. Psychopathia sexualis. Ed. Mediterranee, Roma, 1964.

4. Ellis H. Psicologia del sesso. Newton Compton, Roma, 1970.

5. Freud S. II Perturbante, in: Saggi sull'arte, la letteratura, il linguaggio. Bollati Boringhieri, Torino, 1991.

6. Freud S. Opere. Newton-Compton, Roma, 1992.

7. Reich W. La rivoluzione sessuale. ErreEmme ed., Viterbo, 1992.

8. Reich W. Sessualità e angoscia, SugarCo, Milano, 1983.

9. Deleuze G, Guattari F. L'Anti-Edipo. Einaudi, Torino, 1972.

10. Deleuze G, Guattari F. Millepiani: Capitalismo e schizofrenia. Castelvecchi, Milano, 2003.

11. Marcuse H. Eros e civiltà. Einaudi, Torino, 1967.

12. Marcuse H. L'uomo ad una dimensione. Einaudi, Torino, 1967.

13. Foucault M. La volontà di sapere. Feltrinelli, Milano, 1976.

14. Foucault M. L'uso dei piaceri. Feltrinelli, Milano, 1978.

15. Foucault M. La cura di sé. Feltrinelli, Milano, 1978.

16. Foucault M. Storia della sessualità. Feltrinelli, Milano, 1985. 